
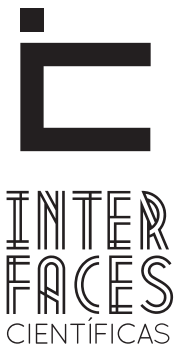

DIREITO

\title{
CRÍTICA AO ATUAL MODELO DE LANÇAMENTO DE IPTU
}

Carlos Horácio Bonamigo Filho ${ }^{1}$

\section{RESUMO}

0 atual modelo de constituição do crédito tributário de IPTU é produto de uma série de exceções ao ato administrativo formal de lançamento. É objeto desta pesquisa a crítica dessas flexibilizações através da sua oposição aos fundamentos históricos e jurídicos do ato administrativo de lançamento de ofício, especialmente em face dos direitos fundamentais de informação, contraditório e do procedimento de autocontrole da administração. Através do emprego das regras do discurso jurídico é possível identificar uma crise de legitimidade do Judiciário em face de exceções à legislação processual administrativa, sem que a respectiva carga argumentativa tenha sido apta a racionalmente afastar direitos fundamentais.

\section{PALAVRAS-CHAVE}

Constituição, imposto sobre a propriedade, Direitos Fundamentais.

\section{ABSTRACT}

The current model of constitution of the tax credit property tax is the result of a number of exceptions of the administrative act formal launch. The aim of this research is to criticize those exceptions through its opposition to the historical and legal foundations of the administrative act of launching craft, in order to keep the fundamental rights of information, contradictory and self-administration procedure. By employing rules of the juridical discourse is possible to identify a legitimacy crisis in the Judiciary because of the exceptions to the administrative procedural law that are carried out arguments able to rationally push away fundamental rights.

\section{KEYWORDS}

Constitution. Property Tax. Fundamental Rights. 


\section{RESUMEN}

El modelo actual de formalización del impuesto territorial es el producto de una serie de excepciones del acto administrativo que formaliza la deuda. El objeto de esta investigación es la crítica de estas excepciones a través de su oposición a los fundamentos históricos y jurídicos del acto administrativo, especialmente en atención a los derechos fundamentales de información, contradictorio y el procedimiento de auto-regulación da Administración. Mediante el empleo de las reglas del discurso jurídico es posible identifi- car una crisis de legitimidad del poder judicial pelas excepciones a la dogmática del procedimiento administrativo, sin que la carga de la argumentación pueda racionalmente distanciar derechos fundamentales.

\section{PALABRAS CLAVE}

Constitución. Impuestos a la Propiedad. Derechos Fundamentales.

\section{INTRODUÇ̃̃O}

A forma de constituição do crédito tributário do Imposto sobre a propriedade territorial e predial urbana (IPTU) recebeu temperamentos, sendo hoje modelo extraordinário de lançamento de ofício.

\section{MODELO ATUAL DE CONSTITUIÇÃO DO CRÉDI- TO TRIBUTÁRIO DE IPTU}

O IPTU é um tributo de liquidação extremamente complexa. Usualmente a legislação dos municípios estipula uma série de especificações, como isenções, exclusões de base de cálculo, alíquotas diferenciadas em razão de progressividade, seletividade ou realização de função social da propriedade, designação do contribuinte e hipóteses de responsabilidade, formas de impugnação, dentre outros itens. A estes elementos de ordem legal, somam-se definições assentadas pela jurisprudência, tornando o IPTU um dos tributos
Este atual modelo de constituição do tributo é objeto de crítica através da sua oposição aos fundamentos históricos e jurídicos do ato administrativo de lançamento de ofício, especialmente em face dos direitos de informação, contraditório e autocontrole da administração. com a sistemática mais obscura do País. ${ }^{1}$

1 Dentre as matérias objeto de uniformização, estão a incidência do ITR, não do IPTU, sobre imóvel localizado na área urbana do Município, desde que comprovadamente utilizado em exploração extrativa, vegetal, agrícola, pecuária ou agroindustrial (REsp 1112646/ SP, Rel. Ministro HERMAN BENJAMIN, PRIMEIRA SEÇÃO, julgado em 26/08/2009, DJe 28/08/2009), bem como que é "defeso, ao Município, atualizar o IPTU, mediante decreto, em percentual superior ao índice oficial de correção monetária." (STJ, Súmula 160). Sobre a sujeição passiva, assentou-se que "o legislador municipal pode eleger o sujeito passivo do tributo, contemplando qualquer das situações previstas no CTN” (AgRg no Ag 1326550/PB, Rel. Ministro LUIZ 
Em síntese, a problemática tem os seguintes contornos: somente é exigível o tributo constituído; dentre as formas possíveis, usualmente o IPTU é constituído por lançamento de ofícióz; o lançamento de ofício é perfectibilizado pela notificação ao contribuinte; o lançamento de ofício é o resultado do procedimento em que a Administração (i) identifica o devedor e os corresponsáveis, (ii) calcula a quantia devida, (iii) expressa o valor originário da dívida e (iv) a maneira de calcular os juros de mora e demais encargos previstos em lei com indicação do respectivo fundamento legal, (v) também mencionando o termo inicial de incidência, bem como (iv) formaliza a origem e natureza do crédito, mencionando a específica disposição da lei em que seja fundado (artigos 142 e 202 do CTN e do $\S 5^{\circ}$ do art. $2^{\circ}$ da $\left.L E F^{3}\right)$.

Contudo, os referidos usuais requisitos do lançamento de ofício (notificação e formalização, em especial) vão de encontro à prática dos Municípios. Isso porque, em geral, a Administração Municipal realiza a quantificação da obrigação tributária anualmente através de sistemas computadorizados lacunosos e de difícil compreensão, concluindo o procedimento de constituição do crédito tributário através de

FUX, PRIMEIRA TURMA, julgado em 21/10/2010, DJe 16/11/2010), e que, neste sentido, o promitente comprador, quando possuir as características do possuidor a qualquer título, pode ser considerado o sujeito passivo.

2 Sendo juridicamente possível a instituição de sistemática de tributação do IPTU submetida ao lançamento por Declaração ou ao lançamento por homologação. Migração do lançamento de ofício ao lançamento por homologação ocorreu no ITR, tributo de sistemática aproximada, quando da lei nº 9.393/96. Da mesma forma, tem-se juridicamente possível a constituição do crédito tributário de IPTU através de declaração do contribuinte que reconheça, por exemplo, em pedido de parcelamento ou em procedimento de denúncia espontânea.

3 Além dos requisitos exigidos especificamente para o lançamento, outros podem ser extraídos da interpretação sistemática do ordenamento. Em especial, chama atenção os requisitos do Termo de Inscrição em Dívida Ativa apurados no processo de lançamento precedente. Isso porque a Inscrição em Dívida Ativa é ato de controle da legalidade que apura a liquidez e a certeza do crédito tributário objeto de constituição precedente (LEF, Art. $\left.2^{\circ}, \S 3^{\circ}\right)$. Assim, os requisitos exigidos para o Termo de Inscrição em Dívida Ativa devem necessariamente estar descritos no lançamento que o precede. notificação ficta por Edital e envio dos carnês de pagamento com descrição incompleta dos elementos exigidos pela Legislação. Ou seja, na generalidade dos casos, os requisitos exigidos pela legislação não são observados.

Quanto à constituição do crédito tributário do IPTU, a jurisprudência uniformizou o entendimento de que não é necessária a notificação pessoal com prova do recebimento em relação ao tributo constituído anualmente. Eis que "o contribuinte do IPTU é notificado do lançamento pelo envio do carnê ao seu endereço" (STJ, Súmula nº 397). Ou seja, “a remessa, ao endereço do contribuinte, do carnê de pagamento do IPTU é ato suficiente para a notificação do lançamento tributário"4, segundo jurisprudência em Recursos Repetitivos pelo Superior Tribunal de Justiça (STJ) ${ }^{5}$.

Nota-se que a jurisprudência acatou um novo procedimento relativo à constituição do crédito tributário de IPTU. Neste contexto, portanto, duas questões paradigmáticas causam grande mal-estar entre a realidade prática da tributação e a legislação: em primeiro lugar, houve a flexibilização do instituto da notificação do lançamento a pretexto de manter a praticabilidade da tributação, como assentado pela jurisprudência; em segundo lugar, a própria realização do ato administrativo formal de lançamento simplesmente não ocorre. Ou seja, ocorre a cobrança de tributo sem

4 REsp 1111124/PR, Rel. Ministro TEORI ALBINO ZAVASCKI, PRIMEIRA SEÇÃO, julgado em 22/04/2009, DJe 04/05/2009

5 Da mesma forma, o STJ dispôs sob o pálio dos Recursos Repetitivos que é faculdade da Administração tributária rever o lançamento exclusivamente em casos de erro de fato relativo ao cadastro do imóvel, jamais em caso de revaloração jurídica decorrente da incidência da regra aos fatos (erro de direito). "A retificação de dados cadastrais do imóvel, após a constituição do crédito tributário, autoriza a revisão do lançamento pela autoridade administrativa." (REsp 1130545/RJ, Rel. Ministro LUIZ FUX, PRIMEIRA SEÇÃO, julgado em 09/08/2010, DJe 22/02/2011). Neste caso de revisão do lançamento, isto é, de lançamento de complemente o anterior (revisto), não há posicionamento uniformizado em relação à forma de constituição definitiva do crédito tributário. Ou seja, existem mais de uma espécie de lançamento de IPTU, o anual e o complementar decorrente de erro de fato relativo à data do fato gerador. 
a existência de lançamento formal. Em regra, os Municípios provocados a fornecer ao contribuinte o lançamento de IPTU se limitam a entregar extratos da dívida ou memórias de cálculo que não contemplam os requisitos do lançamento.

Os fundamentos que suportam a constituição do crédito tributário de IPTU são sintetizados no Recurso Especial no 1.114.780/SC, de relatoria do ministro Luiz Fux, submetido à sistemática dos Recursos Repetitivos.

(a) o proprietário do imóvel tem conhecimento da periodicidade anual do imposto, de resto amplamente divulgada pelas prefeituras;

(b) o carnê para pagamento contém as informações relevantes sobre o imposto, viabilizando a manifestação

\section{CRÍTICA AO MODELO ATUAL DE CONSTITUIÇÃO DO CRÉDITO TRIBUTÁRIO DE IPTU}

São quatro as críticas trazidas em relação ao modelo atual de constituição do crédito tributário de IPTU. (1) É desprezado que o lançamento é uma das formas de controle da legalidade da constituição do crédito tributário através do autocontrole da Administração submetida a procedimento predeterminado e à sistemática própria dos atos administrativos. (2) 0 modelo atual nega ao contribuinte o direito de informação completa sobre a dívida que the é atribuída. (3) 0 modelo impede o obrigado tributário de exercer seu direito ao contraditório também em âmbito administrativo. (4) A quarta crítica trata do desprezo à formalidade legal, existente justamente para que as três primeiras críticas sejam protegidas pelo Judiciário através do mecanismo de Separação de Poderes subjacente ao Princípio da Legalidade. de eventual desconformidade por parte do contribuinte;

(c) a instauração de procedimento administrativo prévio ao lançamento, individualizado e com participação do contribuinte, ou mesmo a realização de notificação pessoal do lançamento, tornariam simplesmente inviável a cobrança do tributo. ${ }^{6}$

Ou seja, a prática criou uma nova espécie de lançamento tributário de ofício, cujo fundamento é a sua praticabilidade. 0 cenário de incontáveis lançamentos anualmente realizados nesta modalidade sui generis, despidos dos requisitos exigidos pela legislação, é objeto de crítica no tópico seguinte.

6 REsp 1114780/SC, Rel. Ministro LUIZ FUX, PRIMEIRA SEÇÃO, julgado em 12/05/2010, DJe 21/05/2010

Frisa-se que a crítica a ser desenvolvida parte de uma concepção de direito tributário de que é direito fundamental do contribuinte não sofrer tributação ilegal ou inconstitucional, não podendo ser flexibilizada a regra legal para justificar o nascimento da obrigação tributária ou a sua cobrança. ${ }^{7}$

Em apertada síntese, diga-se que o interprete é vinculado à semântica da proposição constitucional

70 Direito Fundamental de não pagar tributo irregular está positivado na Constituição portuguesa no art. 103 (Ninguém pode ser obrigado a pagar impostos que não hajam sido criados nos termos da Constituição, que tenham natureza retroactiva ou cuja liquidação e cobrança se não façam nos termos da lei). No ordenamento brasileiro tal regra constitucional é implícita, decorrente dos direitos fundamentais à propriedade, devido processo legal e moralidade administrativa. 
de direitos fundamentais, ainda que esta seja de difícil compreensão por seu caráter aberto. Ainda que se admita a superação do paradigma exclusivamente subsuntivo no Direito Tributário (BONAMIGO, 2011) a inclusão da ponderação como forma de aplicação do direito cria grave insegurança jurídica - implicando na necessidade de descoberta dos novos direitos fundamentais dos contribuintes. Nesse aspecto, a ponderação irá criar exceções a regras jurídicas por determinados argumentos veiculados no discurso jurídico.

Questão interessante a ser respondida é se o processo de ponderação pode igualmente resultar em não incidência de regra jurídica em favor ou contra ao contribuinte. Para a resposta, faz-se o seguinte raciocínio: a flexibilização da regra jurídica incidente sobre o suporte fático atribui o ônus argumentativo àquele a quem interessa a flexibilização. Na tributação, a intenção de impedir o nascimento da obrigação tributária quando realizado o fato gerador demanda grande ônus argumentativo - ocorrerá excepcionalmente, eis que subjazem à regra jurídica tributária princípios de capacidade contributiva, Rule of Law, solidariedade e interesse público, conforme o caso.

Por outro lado, o nascimento da obrigação tributária quando ausente o fato gerador (não ocorrência no mundo dos fatos do previsto expressamente na lei em sentido formal e material), isto é, em favor da Fazen$\mathrm{da}$, a pretexto de existente capacidade contributiva, exige um ônus argumentativo ainda maior, eis que deverão ser veiculados na ponderação os princípios de Separação de Poderes, direito de Propriedade e o Consentimento do Contribuinte à Tributação (subjacentes à regra jurídica), enquanto direitos fundamentais (que protegem exclusivamente o cidadão). Note-se que é possível retirar do texto constitucional conteúdos semânticos que atraem força argumentativa privilegiada. Isto é, em se tratando de direitos fundamentais, o intérprete é vinculado ao texto relativo às disposições constitucionais (ALEXY, 2012, p. 552). Naturalmente, nem sempre a disposição de direito fundamental prevalecerá (será flexibilizada). Contudo, para o jurista superar a vinculação à proposição constitucional de direito fundamental (propriedade, devido processo legal) não é suficiente o argumento de que solução contrária ao texto é mais adequada que a com ele compatível. Isso porque "as razões para a solução contrária devem ser extremamente fortes para que, do ponto de vista da Constituição, o afastamento do teor literal fique justificado" (ALEXY, 2012, p. 553). 0 conteúdo semântico do dispositivo de direitos fundamentais cria um bônus argumentativo em favor de sua preservação.

Por essa interpretação, os princípios que velam pelo crédito tributário cedem com menos dificuldade que princípios que preservam os direitos fundamentais do contribuinte. Ou seja, em face do desenho constitucional de índole preservadora de direitos fundamentais (que militam exclusivamente em favor do cidadão), tem-se que o ônus argumentativo que justifique a constituição do crédito tributário despido do devido processo legal deve ser muito maior que a justificativa de não constituição ou extinção do crédito tributário em face de alguma peculiaridade qualquer. Assim, o exercício de argumentação jurídica poderá resultar no afastamento de regras (flexibilização da legalidade), mas ocorrerá apenas ocasionalmente em favor do contribuinte e muito excepcionalmente em favor da Fazenda, eis que o Estado de Direito e os direitos fundamentais do contribuinte têm força argumentativa mais robusta que o interesse público em relação ao crédito tributário.

Feitas estas ponderações, que se estabeleça o porquê da existência do lançamento. Retomando o paradigma subsuntivo, para Alfredo Augusto Becker os efeitos da regra jurídica sobre os fatos são imediatos e nascem no instante lógico posterior à realização do suporte fático. A exceção ocorre quando outra regra dispõe de outra forma. No direito tributário, nasce a obrigação tributária quando da realização do fato gerador, mas o sistema dispõe que somente será exigível quando procedida a sua constituição definitiva através do lançamento (BECKER, 2010, p. 379). 
Assim, adota-se o entendimento de que o lançamento tem efeito declaratório quanto à ocorrência do fato gerador e constitutivo ao inovar no sistema jurídico e conferir exigibilidade à obrigação tributária. Pode-se identificar na praticidade da tributação uma das razões de existência do lançamento, eis que a obrigação tributária sempre necessitará de liquidação (cálculos aritméticos).

Saldanha Sanches refere relevante função do lançamento, de cunho histórico. Para o autor, a concepção clássica que responsabiliza a Administração pela gestão do nascimento, modificação e extinção da obrigação tributária ${ }^{8}$ é reflexo de uma compreensão de tributação juridicamente disciplinada de caráter protetivo (SANCHES, 2000, p. 26). Nesta linha, o procedimento de lançamento (acto tributário) é o resultado do desenvolvimento da relação entre Administração e contribuintes como "único modo de evitar e limitar as actuações arbitrárias, que a ausência de limites para a actividade estatal amplamente proporciona." (SANCHES, 2000, p. 19) Sob esta concepção, o Lançamento é a fusão da liquidação do tributo com o instituto do ato administrativo, revestido de seu principal requisito de legalidade e formalidade - fusão realizada com o objetivo de concretizar determinada finalidade, a garantia de direitos do cidadão.

O que nos conduz ao problema da existência de um corpo de princípios orientados no sentido da defesa dos direitos e interesses legítimos dos administrados. Inseridos na actuação administrativa e condicionando-a de uma forma permanente, tutelando a expectativa dos particulares a uma actuação pública confinada a determinados parâmetros, juridicamente determináveis. (SANCHES, 2000, p. 26)

Assim, é premissa inicial para entender o papel do lançamento o argumento de que o lançamento é, por excelência, um instituto protetivo que limita os poderes da Administração ao criar formas procedimen-

8 Abandonada ao longo do tempo por sistemática que transfere aos contribuintes os deveres de liquidação e pagamento do tributo, enquanto o lançamento assume a função corretora dos desvios do contribuinte. tais estritos - entendimento que tem eco na doutrina espanhola ${ }^{9}$ e alemã..$^{10}$ Quanto o fiscal tem o dever de identificar fundamento legal, base de cálculo, prova do fato gerador, dentre outros requisitos, fiscaliza a si próprio. 0 procedimento estrito permite seu controle interno (autocontrole), evitando a discricionariedade no nascimento e cobrança do tributo e permite seu controle externo (possibilidade de auditar a liquidação do tributo).

No Brasil ${ }^{11}$ a legislação tributária descreve o procedimento a ser adotado; contudo, a Administração vem continuamente relativizando o instituto do lançamento de ofício - despindo o contribuinte de sua garantia de que a Administração irá submeter-se ao autocontrole subjacente às regras do procedimento que resulta no lançamento. Neste contexto, o contribuinte está submetido a situação kafkaniana: por razões além de seu controle, ao ser surpreendido por cobranças de IPTU não tem condições de auditar o cálculo de liquidação do tributo, bem como não tem condições de verificar a fundamentação legal da obrigação imposta - em situação de extrema fragilidade em face de tributo com sistemática altamente complexa.

9 No direito espanhol, José Juan Ferreiro Lapatza refere "gestionar o aplicar los tributos significa no lólo determinar las concretas obligaciones que derivan de las normas que los estabelecen y ejecutar tales obligaciones, sino también procurar que la determinación y ejecucion de estas obligaciones se realice conforme el mandato de la ley, evitando y corrigiendo em lo posible toda desviación (LAPATZA, 1989, p. 571).

10 No direito alemão, Tipke enfatiza "Ao processo fiscal é, como determinam os $\S \S 44 \mathrm{FGO}$; §§ff. Ff. VwGO, conectado um procedimento preparatório (Vorverfahren), no qual a própria autoridade deve examinar se ela aplicou o direito corretamente e exerceu corretamente uma discricionariedade a ela permitida" (TIPKE, 2008, p. 99). 11 Também há manifestações na doutrina brasileira sobre o caráter de autocontrole da administração através do processo administrativo que resulta no lançamento. "A importância dessa atividade é ressaltada pelo fato de que, além de servir para determinar, concretamente, as obrigações tributárias e executá-las, a Administração Pública está a praticar o controle de legalidade de cada um dos atos por ela emitidos" (HORVATH, 2010, p. 44) 
Pondera-se que a massificação da gestão tributária traz complicadores. Ainda assim, não é possível extrair da Constituição princípios hábeis a flexibilizar a regra jurídica que provoca o autocontrole subjacente ao procedimento de lançamento, dá forma ao ato administrativo e possibilita o controle externo da Administração ${ }^{12}$ através do estrito procedimento exigido para o lançamento de ofício ${ }^{13}$. Pelo contrário, o devido processo legal (direito fundamental), pressupõe notificação formal (não o conhecimento meramente ficto) e o conhecimento ao contribuinte de seu direito de impugnação. Ou seja, a quem interessa flexibilizar o instituto do lançamento de ofício é atribuído o ônus argumentativo qualificado (por afastar o direito fundamental ao devido processo legal e o direito de informação).

Veja-se que o lançamento é, antes de tudo, um ato administrativo ${ }^{14}$ - que pode ser precedido de processo

12 Com acuidade, Paulo de Barros Carvalho refere "Realmente, para que se dê por instalada a relação jurídica do tributo faz-se necessário utilizar as formas de linguagem previstas pela legislação, indicando os sujeitos do vínculo (ativo e passivo), determinado a base de cálculo (grandeza apta para dimensionar as proporções jurídicas do fato), bem como apontando para a alíquota que há de conjugar-se com a matéria imponível, para compor o quantum debeatur. É claro que somente após esse empenho de formalização em linguagem própria é que o titular do direito subjetivo terá condições de exercitá-lo, reivindicando-o perante o sujeito passivo, já agora devidamente identificado no consequente da norma individual e concreta". Isto é, é necessária a formalização da identificação do suporte fático (antecedente) e dos cálculos aritméticos de quantificação do tributo (consequente) - com a menção do respectivo fundamento legal, enquanto ato administrativo motivado e formal. (CARVALHO, 2011, p. 472)

13 “[...] certo é que do documento que formaliza o lançamento deve constar referência clara a todos estes elementos, fazendo-se necessário, ainda, a indicação inequívoca e precisa da norma tributária impositiva incidente." (PAULSEN, 2011, p. 1059)

14 Conforme também Paulo de Barros Carvalho, que identifica o lançamento como "ato jurídico administrativo, da categoria dos simples, constitutivos e vinculados, mediante o qual se insere na ordem jurídica brasileira u'a norma individual e concreta, que tem como antecedente o fato jurídico tributário e, como consequente, a formalização do vínculo obrigacional pela individualização dos sujeitos ativo e passivo, a determinação do objeto da prestação, formado pela base de cálculo e correspondente alíquota, bem como pelo estabelecimento dos termos espaço-temporais em que o crédito há de ser exigido". (op. cit., p. 464) administrativo ou não. Naturalmente, enquanto ato administrativo, deve reunir todas as características próprias deste instituto ${ }^{15}$, em especial fundamentação (motivo) e formalidade (forma). Ou seja, o lançamento deve expressar em seu bojo necessariamente "a situação de direito ou de fato que determina ou autoriza a realização do ato administrativo" (MEIRELLES, 2008, p. 156) (motivo), bem como deve-se notar que o "revestimento exterior do ato administrativo constitui requisito vinculado e imprescindível à sua perfeição." (MEIRELLES, 2008, p. 156). Em regra, o ato administrativo é formal e "a inexistência da forma induz à inexistência do ato administrativo" (MEIRELLES, 2008, p. 156).

Todos estes elementos se relacionam com o direito à informação do contribuinte. É direito fundamental individual o direito de receber dos órgãos públicos informações de seu interesse particular (CF, art. $5^{\circ}$, XXXIII ${ }^{16}$ ), o que se manifesta no direito tributário na garantia de formalização da liquidação do tributo em ato formal com os requisitos exigidos pela legislação tributária.

Neste contexto, é de difícil conciliação o posicionamento da jurisprudência com as premissas constitucionais garantidoras do direito ao devido processo legal e direito de informação.

A jurisprudência é conivente com a flexibilização do instituto do lançamento - em especial em relação a sua exteriorização (requisito do ato administrativo) ao não exigir notificação formal do contribuinte do ato administrativo de lançamento que the impõe a obrigação tributária. ${ }^{17}$ Isso sem que exista na legis-

15 Em síntese, são requisitos do ato administrativo a competência, a forma, o motivo e o objeto (MEIRELLES, 2008, p. 156; MEDAUAR, 2010, p. 143 e 144)

$16 \mathrm{CF}$, art. $5^{\circ}, \mathrm{XXXIII}$ - todos têm direito a receber dos órgãos públicos informações de seu interesse particular, ou de interesse coletivo ou geral, que serão prestadas no prazo da lei, sob pena de responsabilidade, ressalvadas aquelas cujo sigilo seja imprescindível à segurança da sociedade e do Estado.

17 A comunicação formal é um dos requisitos de forma do ato administrativo. 
lação complementar ${ }^{18}$ disposição que excepcione tal necessidade. Isto é, a pretexto de garantir a praticabilidade da tributação, suprime-se o direito de acesso à informação através da notificação formal fundamentada com os requisitos exigidos pela legislação e informação sobre o direito fundamental de iniciar o contraditório administrativo (CF, Art.50, LV'19).

Especialmente problemático é que a jurisprudência não se desincumbiu de seu ônus argumentativo, aplicando de maneira talvez intuitiva um princípio de praticabilidade da tributação. 0 não enfrentamento dos argumentos legais e constitucionais torna difícil uma uniformidade intersubjetiva e criam uma crise de legitimidade subjacente ao autoritarismo decorrente da decisão deficientemente fundamentada. 0 posicionamento, contudo, hoje se assenta no argumento de autoridade subjacente ao rito dos Recursos Repetitivos $^{20}$. Ainda que se contemple que o direito admite mais de uma resposta aos problemas que se apresentam, é indispensável que as decisões mantenham a sua racionalidade através do enfrentamento dos argumentos contrários e fundamentação das decisões, que é, lembre-se, ordem constitucional. ${ }^{21}$

Veja-se que o próprio teste de proporcionalidade sugere solução diversa da empregada pelo

18 Somente a lei complementar pode dispor sobre o lançamento e a constituição do crédito tributário, na forma do art. 146, III, 'c', da Constituição.

$19 \mathrm{CF}$, art. 50, LV - aos litigantes, em processo judicial ou administrativo, e aos acusados em geral são assegurados o contraditório e ampla defesa, com os meios e recursos a ela inerentes;

20 Isso porque o discurso jurídico encontra limitações no direito vigente e é ônus argumentativo daquele com intenção de contrariam a jurisprudência o ônus argumentativo que assim justifique. (ALEXY, 2011, p. 211 e 268)

21 CF, Art. 93. Lei complementar, de iniciativa do Supremo Tribunal Federal, disporá sobre o Estatuto da Magistratura, observados os seguintes princípios: [...] IX todos os julgamentos dos órgãos do Poder Judiciário serão públicos, e fundamentadas todas as decisões, sob pena de nulidade, podendo a lei limitar a presença, em determinados atos, às próprias partes e a seus advogados, ou somente a estes, em casos nos quais a preservação do direito à intimidade do interessado no sigilo não prejudique o interesse público à informação;
STJ. Todo ato estatal é passível de teste de sua proporcionalidade, devendo ser idôneo, necessário e exigível (proporcional em sentido estrito) (TIPKE, 2008, p. 270-271). É idôneo o ato quando o fim é atingido através do meio empregado; é necessário quando o meio empregado é aquele que, dentre os meios idôneos, é o menos oneroso em relação a direitos fundamentais; por fim, é exigível quando o fardo relativo ao obrigado não é exagerado a ponto de não justificar a ação estatal.

No caso em estudo, a finalidade almejada pelo Fisco é a praticabilidade, a exequibilidade da tributação. O meio empregado é o lançamento de ofício anual com notificação ficta e sem a formalização das informações exigidas pela legislação. 0 meio empregado atinge o fim almejado (teste de idoneidade); contudo, existem outros meios hábeis a atingir o fim que restringem menos direitos fundamentais (teste de necessidade). Da mesma forma, o meio empregado atinge o núcleo duro do direito fundamental de informação e contraditório administrativo, não se mostrando exigível. Por exemplo, são meios alternativos de realização de tributação exequível a modificação do sistema de constituição do crédito tributário para o lançamento por homologação ${ }^{22}$ ou a parametrização do sistema computadorizado de forma a contemplar as informações exigidas, garantindo uma forma de autocontrole mais rígido do procedimento. Veja-se que se a Fazenda tem condições de apurar a ocorrência do fato gerador através do cadastro de imóveis e de quantificar o imposto, substituindo a ação humana - que a programação contemple os demais requisitos exigidos pela legislação e que através de lei se outorgue o efeito de ato administrativo ao resultado do processo de burilamento informático que resultado da apuração do tributo, permitindo o recebimento pelo contribuinte de notificação apta a cumprir os requisitos para os quais o lançamento foi idealizado: (i) auto regulação da administração subjacente ao procedimento de parametrização do sistema à legislação e no caso de al-

22 Como procedido com o Imposto Territorial Rural através da Lei n० $9.393 / 1996$. 
teração do cadastro de imóveis, (ii) clareza em relação à liquidação do tributo, permitindo a auditoria dos cálculos, (iii) informação ao contribuinte, garantindo-lhe direito de acesso ao contraditório administrativo. Nada disso é contemplado nos sistemas informáticos sobre os quais assenta-se a tributação de IPTU na generalidade dos municípios.

Por fim, chama-se atenção à teleologia da submissão da Administração à Legalidade. A observância da lei não é um fim em si mesmo, mas um instrumento de preservação de um bem maior: a proteção de direitos fundamentais. A história demonstrou que é desastro- sa a concentração de poder, daí a evolução até a Separação de Poderes, indissociável ao Estado de Direito. Através do legislador, o contribuinte consente com a tributação e com a forma de cobrança. Desta forma o sistema jurídico limita o poder do Executivo. Ao Judiciário cabe garantir o império do direito, concretizando a axiologia constitucional através da fiscalização da Administração Tributária, exigindo o cumprimento da lei (instrumento de realização da vontade democrática e limitação do poder). A flexibilização da regra para permitir o nascimento da obrigação tributária ou a cobrança de tributo exige argumentos que fundamentem o seu afastamento.

\section{CONCLUSÃO}

0 modelo atual de constituição do crédito tributário de IPTU é caracterizado pela não observância de formalidades garantidoras dos direitos fundamentais de autocontrole da Administração, informação e contraditório administrativo, em favor da praticabilidade da tributação - como se estes diversos elementos fossem contraditórios.

Nota-se a complacência do Judiciário com as irregularidades que transfiguraram o instituto do lançamento de ofício, criando verdadeira nova espécie de constituição do crédito tributário, despida de necessidade de notificação, de descrição compreensível da liquidação do tributo ou de informação sobre o direito de contraditório administrativo através de impugnação.

A crítica do modelo atual ocorre em dois níveis. Em âmbito administrativo, frisa-se que é falacioso o argumento que a praticabilidade da constituição do crédito tributário de IPTU não convive com as garantias fundamentais correntes dos contribuintes em face do Estado. Os sistemas computadorizados hábeis à apu-

ração do fato gerador e quantificação da obrigação tributária igualmente tem condições de identificar e formalizar de maneira inteligível os requisitos do lançamento de ofício, bem como o procedimento de notificação é trivial. Há expressa opção por não realização do procedimento usual.

Em um segundo nível, a crítica é dirigida à atuação do Judiciário que flexibiliza regras jurídicas sem desincumbir-se de seu ônus argumentativo ao acolher argumentos de praticabilidade da tributação sem justificar o afastamento de direitos fundamentais como de acesso à informação, contraditório administrativo, bem como deixa de fundamentar a justificativa para a supressão dos requisitos de forma e motivo do ato administrativo. Ao assim proceder, o Judiciário deixa de exercer seu papel de contrapeso ao poder do Executivo, resultando em tributação sem consentimento, materialmente inconstitucional (no taxation without representation), tornando o contribuinte impotente e fragilizado em face da brutalidade potencial do poder ilimitado. 


\section{REFERÊNCIAS}

ALEXY, Robert. Teoria dos Direitos Fundamentais. Tradução de Virgílio Afonso da Silva. 2. ed. 2. tiragem. São Paulo: Malheiros, 2012. p. 552.

ALEXY, Robert. Teoria da Argumentação Jurídica. A Teoria do Discurso Racional como Teoria da Fundamentação Jurídica. 3 ed. Rio de Janeiro: Forense, 2011.

BECKER, Alfredo Augusto. Teoria Geral do Direito Tributário. 5. ed. São Paulo:Noeses, 2010.

BONAMIGO FILHO, Carlos Horácio. Além da Legalidade: 0 exame de juridicidade no Direito Tributário. Estudo da Incidência de ICMS enquanto vigente acordo interestadual autorizando benefício fiscal. Revista de Direito Tributário da APET. a. VIII, ed. 31, set.2011, p. 13-41.

BRASIL. Superior Tribunal de Justiça. Agravo Regimental no Agravo de Instrumento nº 1.326.550/PB, Rel. Ministro LUIZ FUX, PRIMEIRA TURMA, julgado em 21/10/2010, DJe 16/11/2010.

BRASIL. Superior Tribunal de Justiça. Recurso Especial no 1.111.124/PR, Rel. Ministro TEORI ALBINO ZAVASCKI, PRIMEIRA SEÇÃO, julgado em 22/04/2009, DJe 04/05/2009

BRASIL. Superior Tribunal de Justiça. Recurso Especial n 1.112.646/SP, Rel. Ministro HERMAN BENJAMIN, PRIMEIRA SEÇÃO, julgado em 26/08/2009, DJe 28/08/2009.

BRASIL. Superior Tribunal de Justiça. Recurso Especial n 1.130.545/RJ, Rel. Ministro LUIZ FUX, PRIMEIRA SEÇÃO, julgado em 09/08/2010, DJe 22/02/2011

CARVALHO, Paulo de Barros. Curso de Direito Tributário. 23. ed. São Paulo:Saraiva, 2011

HORVATH, Estevão. Lançamento Tributário e “Autolançamento”. 2. ed. ver. e ampl. São Paulo:Quartier Latin, 2010

LAPATZA, José Juan Ferreiro. Curso de Derecho Financeiro Español. 11. ed. Madrid:Marcial Pons, 1989.

MEDAUAR, Odete. Direito Administrativo Moderno. 14. ed. ver. e atual. São Paulo:Revista dos Tribunais, 2010 MEIRELLES, Hely Lopes. Direito Administrativo Brasileiro. 34. ed. São Paulo:Malheiros, 2008

PAULSEN, Leandro. Direito Tributário. Constituição e Código Tributário à luz da doutrina e da jurisprudência. 13. ed., 2011 
SANCHES, José Luís Saldanha. A Quantificação da Obrigação Tributária: Deveres de Cooperação, Autoavaliação e Avaliação Administrativa. 2. ed. Lisboa:LEX, 2000.

TIPKE, Klaus; LANG, Joachim. Direito Tributário. v. I. Porto Alegre:Sergio Antônio Fabris, 2008. 